\title{
EXPERIÊNCIAS SOCIOINTERACIONAIS MEDIADAS PELA TERTÚLIA LITERÁRIA DIALÓGICA
}

\author{
Sociointerational experiences mediated by Dialogic Literary Tertulia
}

\author{
Geovane César dos Santos ALBUQUERQUE (SEEDF) ${ }^{1}$ \\ Ana Paula Santiago Seixas ANDRADE (IFB) ${ }^{2}$ \\ Juliana Harumi Chinatti YAMANAKA (IFB) ${ }^{3}$ \\ Simone Braz Ferreira GONTIJO (IFB) ${ }^{4}$
}

\begin{abstract}
RESUMO: O presente estudo de caso teve como objetivo analisar as experiências sociointeracionais mediadas pela Tertúlia Literária Dialógica (doravante TLD), a partir de uma abordagem interseccional. A TLD é uma metodologia para leitura e interpretação de textos feita de forma coletiva. Ela foi utilizada numa disciplina de Literatura Hispano-Americana II do curso de Licenciatura em Letras/Espanhol, ofertado por uma instituição de ensino pública federal, durante o primeiro semestre de 2016 . De caráter exploratório, o presente estudo de caso foi edificado sobre o paradigma da investigação qualitativa-interpretativista e contou com a realização de pesquisa bibliográfica, observacional, bem como com a aplicação de entrevistas semiestruturadas realizadas com quatro estudantes, que cursaram a disciplina. De acordo com as narrativas analisadas, a TLD contribuiu para a promoção de momentos e espaços dialógicos nos quais os participantes puderam manifestar suas percepções de mundo construídas a partir de seu lugar de existência.
\end{abstract}

PALAVRAS-CHAVE: Experiências sociointeracionais; Interseccionalidade; Tertúlia Literária Dialógica.

ABSTRACT: The present case study had as objective to analyze the sociointerational experiences mediated by the Dialogical Literary Dialogue (hereafter TLD), from an intersectional approach. The TLD is a methodology for reading and interpreting texts done collectively. It was used in the discipline Hispanic-American Literature II in Spanish Language undergraduate program, offered by a federal public institution, during the first semester of 2016. Of an exploratory nature, the present case study was built on the paradigm of the qualitative-interpretative research and counted on the accomplishment of bibliographical, observational research, as well as the application of semistructured interviews with four students who studied the discipline. According to the narratives analyzed, the TLD contributed to the promotion of dialogical moments and spaces in which the participants could express their perceptions of the world constructed from their place of existence.

KEYWORDS: Intersectionality; Dialogic Literary Tertulia; Sociointerational

\footnotetext{
${ }^{1}$ Licenciado em Letras/Espanhol pelo IFB e docente na Secretaria de Educação do Distrito Federal (SEEDF).

${ }^{2}$ Mestra em Educação Social e Intervenção Comunitária pelo Instituto Politécnico de Santarém e técnica em assuntos educacionais do Instituto Federal de Brasília (IFB).

${ }^{3}$ Mestra em Linguística Aplicada pela Universidade de Brasília (UnB) e docente no Instituto Federal de Brasília (IFB). Email: julianalapsis@ gmail.com

${ }^{4}$ Doutora em Educação pela Universidade de Brasília $(\mathrm{UnB})$ e docente no Instituto Federal de Brasília (IFB).
} 
experiences.

\section{INTRODUÇÃO}

A Tertúlia Literária Dialógica (doravante TLD) é uma metodologia para leitura e interpretação de textos realizada de forma coletiva por meio da socialização das experiências de vida das pessoas que participam de encontros regulares. Surge no período de Pós-Guerra Civil Espanhola, no Centro deeducación de personas adultas de La Verneda de Sant Martí, num bairro popular de Barcelona. É teorizada pelo professor de educação de jovens e adultos Ramón Flecha, que toma como base elaborações do brasileiro Paulo Freire e do alemão Jürgen Habermas.

Em 2011, no Brasil, a TLD passa a ser utilizada no Programa Mulheres Mil, na formação de mulheres em situação de vulnerabilidade social, experiência que trouxe inovações para a metodologia, descritas por Andrade e Pereira (2014) no guia didático Tertúlia Literária Dialógica: teoria e prática. No guia, as autoras dialogam com as elaborações de Flecha (1997) sobre implicações e possibilidades que a metodologia proporciona aos participantes, além de acrescentarem suas contribuições de pesquisas junto a experiências que resultam em tecnologias sociais que podem ser utilizadas de forma conjunta com a TLD. As autoras refletem sobre o comportamento das participantes em sala durante os encontros e relatam que algo muito presente era o silêncio que se estendia por longos períodos no grupo, principalmente nos primeiros contatos em sala de aula. Segundo elas,

[o] silêncio era algo também muito marcante no comportamento das participantes da TLD, pois o seu lugar de fala no mundo estava vetado pela sua condição social, de raça e de gênero. Assim, elas não falavam quase nada sobre si e suas questões, porque nunca lhes foi dado esse espaço, e sua voz nunca foi considerada nas decisões políticas, na relação com seu companheiro ou na comunidade de modo geral. Isso refletia uma imensa tristeza e baixa estima que contaminavam as primeiras falas. Entretanto, aos poucos estas vozes foram se tornando mais claras, mais audíveis, mais conectadas com quem realmente eram. (ANDRADE; PEREIRA, 2014, p. $115)$.

Nesse fragmento, encontra-se o termo lugar de fala, além de uma breve reflexão sobre a possível relação entre ele, o silêncio percebido nos primeiros encontros e as características socioeconômicas das participantes. Nesse mesmo trecho, as autoras atribuem o aumento e a maior elaboração nas participações não apenas à rotina dos 
REVISTA X, Curitiba, volume 14, n.3, 158-173, 2019.

encontros, mas, ao trabalho realizado, baseado na aprendizagem dialógica, que promove transformações nas alunas e questionamentos sobre seu espaço na sociedade. Magalhães (2017) também menciona o termo lugar de fala duas vezes em sua dissertação de mestrado que observava as relações entre TLD e questões identitárias.

Flecha (1997) reflete sobre esse aspecto quando afirma que são elaboradas teorias sobre déficits de alunos que não pertencem ao grupo formado por homens ocidentais, brancos e jovens, referindo-se à sobreposição dos conhecimentos difundidos por esse movimento identitário sobre os demais durante um longo período da história da humanidade. Esse fenômeno revela o poder vigente na construção de descrições, classificações e proposições de modelos interpretativo sobre o mundo (enquanto uma parcela populacional é silenciada), o que contribui para a manutenção das assimetrias entre os diferentes sujeitos.

Griotto e Mello (2012) falam sobre a importância da incorporação de outras vozes, recordam que a solidariedade proposta por Flecha "abriria o caminho para a contemplação da unidade na diversidade, cabendo as diferentes opiniões e maneiras de falar" (GRIOTTO; MELLO, 2012, p. 77) e salientam que não se deve priorizar alguma fala em detrimento de outra.

Por sua vez, Albuquerque (2016) menciona a dificuldade que uma das participantes de pesquisa teve para falar sobre sua produção escrita, baseada nas experiências durante meditações que antecediam à TLD, ainda que estivessem num ambiente que visava proporcionar o acolhimento. Já, para Gontijo et al (2016), a importância da TLD reside na superação de modelos de educação em que o aluno não tem voz, trazendo novamente a necessidade de refletir sobre o que seria este espaço em que o aluno tem sua fala acolhida e como isso pode se relacionar com a TLD.

Após observar as referências ao lugar de fala dos participantes da TLD em diversos relatos de experiências pedagógicas, foi que se estabeleceu como objetivo geral compreender as experiências sociointeracionais mediadas pela Tertúlia Literária Dialógica, a partir de uma abordagem interseccional. Como objetivos específicos foram propostas s seguintes questões: 1) descrever os participantes da pesquisa a partir da compreensão da relação entre categorias da diferença; 2) analisar as experiências narradas por estudantes de graduação, a partir desses conceitos e 3) compreender possíveis implicações entre categorias da diferença e as experiências mediadas pela TLD. 
REVISTA X, Curitiba, volume 14, n.3, 158-173, 2019.

\section{PERSPECTIVAS TEÓRICAS}

Este trabalho se insere na linha de pesquisa sobre Processos Formativos de Professores e Aprendizes de Línguas no âmbito da Linguística Aplicada. Assim, com vistas à criação de um percurso que levasse à melhor compreensão dos termos e conceitos aqui abordados, optou-se pela divisão desta seção em quatro subseções, que versam sobre: Linguagem, como lugar de interação social; Interseccionalidade, como estratégia teórico-metodológica que compreende a dinâmica dos diversos eixos de poder que posicionam os diferentes sujeitos e Tertúlia Literária Dialógica, enquanto prática pedagógica para a leitura e discussão coletiva de textos literários.

\section{A Linguagem enquanto inter-ação}

No âmbito deste estudo, seguimos a proposta de Koch (2000, p. 7), quando afirma a linguagem "[...] como forma de ação [...]; como lugar de interação que possibilita aos membros de uma sociedade a prática dos mais diversos tipos de atos, que vão exigir dos semelhantes reações e/ou comportamentos, levando ao estabelecimento de vínculos $[\ldots]$ ”.

Essa percepção sobre linguagem impacta as produções científicas porque permite a criação de novas teorias que reconsiderem as atividades humanas e suas orientações hierarquizantes, informadas por um "conjunto de saberes partilhados, construído, na maior parte das vezes, de modo inconsciente, pelos indivíduos pertencentes a um dado grupo social" (CHARAUDEAU, 2001, p.26). Assim, para que possamos aperfeiçoar as práticas pedagógicas visando projetar uma sociedade menos assimétrica, é preciso considerar as relações desiguais de poder que se constituem na e pela linguagem, de modo a perceber que "entre práticas linguísticas, práticas corporais e processos coloniais, surgem, ao mesmo tempo, a reflexão sobre o papel das línguas, especialmente coloniais padronizadas, na dominação racial, de classe e de gênero e a crítica às formas como o pensamento ocidental as define”. (PINTO, 2011, p. 79).

\section{A Interseccionalidade como alternativa investigativa}

Utilizado pela primeira vez por Kimberlé Williams Crenshaw, numa pesquisa sobre violências contra mulheres nos Estados Unidos, a interseccionalidade tem como objeto de investigação as interações vividas pelas pessoas que são discriminadas e/ou 
REVISTA X, Curitiba, volume 14, n.3, 158-173, 2019.

dominadas, ao mesmo tempo, por diferentes eixos de poder, como gênero, raça, classe social etc. (MOUGEOLLE, 2015).

Ao contrário do que afirmava o feminismo da chamada "segunda onda", para o qual a luta de classes era a causa de outras formas de exploração (BIROLI; MIGUEL, 2015), existem outros fatores que levam à precarização da vida e que, por estarem mutuamente implicados, devem ser igualmente considerados. Dessa forma, a interseccionalidade trata das múltiplas posições assumidas pelos sujeitos nos processos interacionais, de modo a reconhecer a heterogeneidade intragrupo e propor a visibilidade das diversas cargas de opressões suportadas por sujeitos localizados em lutas diversas as quais, por vezes, possuem em comum o traço de não pertencimento ao estabelecido como "padrão" na sociedade.

A forma de existência imposta como modelo a ser seguido foi baseada num grupo que possuía como características ser: homem, cisgênero ${ }^{5}$, branco, de classe social elevada e heterossexual. O chamado "sujeito universal" foi ponto de partida para a produção do conhecimento no mundo ocidental, implicando construção de discursos que se propagaram na sociedade e na elaboração das teorias que partiam de determinado ponto de vista, em detrimento de outros (BIROLI; MIGUEL, 2015; RIBEIRO, 2017).

Diante disso, questionando as teorias totalizantes, parte-se da seguinte reflexão: “as formas de opressão não atingem os indivíduos isoladamente, mas também não o fazem somadas ou acopladas, em dinâmicas que permitiriam visualizar cada eixo de opressão separadamente para então compreender [...] os efeitos de sua co-presença". (BIROLI; MIGUEL, 2015, p. 47). A interseccionalidade é percebida, então, como uma possibilidade capaz de abarcar as diversas marcas, ou categorias da diferença, que os indivíduos possuem, para que se possa identificá-los e tecer reflexões sobre como a compreensão deles é desenvolvida, com vistas à criação de estratégias para romper com os paradigmas de subordinação da vida. A compreensão sobre o conceito de interseccionalidade se relaciona à noção de lugar de fala.

O conceito de lugar é visto em distintas áreas e não necessariamente se relaciona à ocupação ou delimitação de um espaço físico, podendo também estender-se a uma ocupação ou delimitação social. Já a fala remete ao entendimento "nem estritamente lingüístico, nem exclusivamente sociológico. Não diz respeito ao contexto, mas ao lugar construído pelo discurso neste contexto”. (BRAGA, 2000 apud AMARAL, 2005, p.

${ }^{5}$ Cisgênero é o indivíduo que se identifica com o sexo biológico com que nasceu e com os padrões sociais atribuídos a ele como roupa, postura, tom de voz etc. 
106).

O lugar de fala provoca a reflexão sobre o fato de que os indivíduos são percebidos como pertencentes a grupos classificados e ordenados socialmente de modo assimétrico, o que concede privilégios para alguns e não para outros, fenômeno que se reproduz no ambiente escolar (hooks, 2013) ${ }^{6}$. Esse termo pode auxiliar a localizar e dar visibilidade às pessoas para que falem por si, em vez de serem faladas por um grupo dominante. Nesse sentido, lugar de fala remete, então, à localização social a partir da qual se "é possível debater e refletir criticamente sobre os mais variados temas presentes na sociedade" (RIBEIRO, 2017, p. 86), sem que haja necessidade de intermediadores, o que implica em repensar o lugar historicamente ocupado pelos grupos privilegiados que têm falado sobre pessoas silenciadas, objetificando-as e tratando-as como meros "informantes nativos" (hooks, 2013, p. 62). Assim, para além de uma visão essencialista sobre quem pode ou deve falar sobre determinado assunto (RIBEIRO, 2017, p. 64), o termo se constitui enquanto estratégia para que os diferentes sujeitos possam repensar seu lugar social, configurando-se como um "reposicionamento na cena e no diálogo social" (FRANÇA, 2001, p. 6), especialmente importante para as minorias, entendidas enquanto identidade que reconhece sua exclusão social como "uma recusa de consentimento, é uma voz de dissenso em busca de uma abertura contra-hegemônica no círculo fechado das determinações societárias. É no capítulo da reinvenção das formas democráticas que se deve inscrever o conceito de minoria”. (SODRÉ, 2005, p. 2). Para facilitar a compreensão do que é o lugar de fala, propõe-se a figura abaixo:

Figura 1 - O lugar de fala.

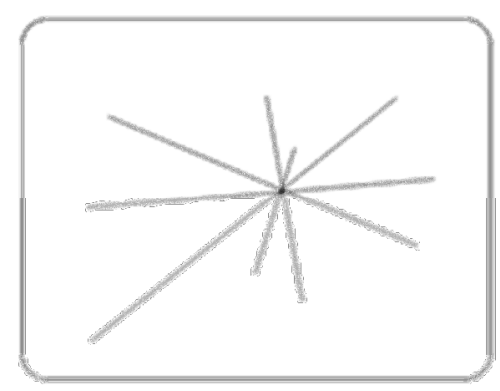

Fonte: Elaborada pelos autores.

A Figura 1 apresenta lugar de fala como o ponto de encontro entre os diferentes eixos de força, levando-se em consideração o contexto no qual serão analisados os discursos. Na escola, pode-se utilizar desse conceito para a compreensão dos

\footnotetext{
${ }^{6}$ Conforme preferência da autora, registramos seu pseudônimo (bell hooks) sempre em letras minúsculas.
} 
REVISTA X, Curitiba, volume 14, n.3, 158-173, 2019.

silenciamentos que alunos ou grupos de alunos podem vivenciar, além de servir como base para que se pense na reestruturação e ressignificação desse espaço.

\section{A Tertúlia Literária Dialógica como possibilidade pedagógica}

A Tertúlia Literária Dialógica (TLD), conforme proposto por Flecha (1997) refere-se à junção das palavras Tertúlia, de origem espanhola, utilizada para referir-se a encontros de amigos para conversas e recreação; Literária, que se deve à utilização de textos literários reconhecidos por seu elevado valor estético; e Dialógica, porque reconhece os diversos saberes e sujeitos para a construção diálogo.

As superações e demais características aqui descritas sobre as potencialidades da TLD se devem aos sete princípios propostos por Flecha (1997): Diálogo igualitário: entendido como a capacidade do ser humano para comunicar-se utilizando-se de argumentação válida, valorizando-o independentemente de sua posição social, idade, gênero, ao ser ouvido e respeitado pelos demais participantes; Inteligência cultural: relacionada às experiências que cada pessoa acumula durante suas vivências, compreendendo os conhecimentos socialmente construídos com o mesmo valor dos que surgem nos ambientes acadêmicos; Transformação: é vista como a capacidade humana de se modificar e modificar a natureza, pois não é um ser que simplesmente se adapta às condições que lhes são impostas; Dimensão instrumental: é a potência que a TLD adquire em espaços de educação formal, com vistas à sua autonomia em diversos contextos; Solidariedade: é um aspecto desenvolvido pelo convívio nos encontros regulares a partir das experiências compartilhadas; Criação de sentido: é o resultado de sentir-se pertencente a um grupo no qual se interage de modo dialógico; Igualdade de diferenças: se refere à tomada de consciência sobre as individualidades que são característica de cada ser humano, tornando cada um único e, por isso, igual aos demais. A esses sete princípios acima descritos, propõem-se um oitavo princípio: a Fruição Artística (ANDRADE; PEREIRA, 2014; GONTIJO et al, 2016), por levar em consideração a necessidade de expressão, inerente ao ser humano.

\section{PERCURSO METODOLÓGICO}

De caráter exploratório, o presente estudo de caso foi edificado sobre $\mathrm{o}$ paradigma da investigação qualitativa-interpretativista e contou com a realização de pesquisa bibliográfica, observacional, bem como com a aplicação de entrevistas 
REVISTA X, Curitiba, volume 14, n.3, 158-173, 2019.

semiestruturadas, gravadas em áudio e posteriormente transcritas. A interpretação do material coletado foi orientada pela análise baseada numa concepção do discurso que entende a palavra como ação, não podendo ser visto como um simples dado, pois "[o] discurso não é um produto acabado, mas um momento num processo de elaboração, com tudo o que isso comporta de contradições, de incoerências, de imperfeições". (BARDIN, 2016, p. 218). Além disso, a análise levou em consideração a triangulação entre experiências relatadas pelos estudantes na entrevista semi-estruturada, as observações realizadas, bem como as notas de campo produzidas durante a etapa observacional.

Nessa pesquisa, colaboraram voluntariamente quatro pessoas, após terem recebido explicação sobre a participação no projeto e assinado Termo de Consentimento Livre e Esclarecido. O critério para seleção do grupo foi ter cursado a disciplina de Literatura Hispano-Americana II, do curso de Licenciatura em Letras com habilitação em Língua Espanhola de uma instituição de ensino pública federal, durante o primeiro semestre de 2016. A seguir, apresentamos uma breve descrição dos colaboradores:

Quadro 1 - Intervenções pedagógicas

\begin{tabular}{|l|c|c|c|c|c|}
\hline Pseudônimo & Gênero & \multicolumn{1}{|c|}{ Idade } & Cor & Semestre & $\begin{array}{c}\text { Havia estudado espanhol } \\
\text { antes do curso de Letras? }\end{array}$ \\
\hline Dalia & 20 & Branca & $7^{\circ}$ & Sim \\
\hline Margarita & 30 & Branca & $7^{\mathbf{0}}$ & Não \\
\hline Nardo & 40 & Pardo & $3^{\mathbf{0}}$ & Não \\
\hline Rosa & 40 & Branca & $7^{\circ}$ & Não \\
\hline
\end{tabular}

Fonte: Elaborado pelos autores.

O planejamento metodológico da disciplina contemplou a ementa proposta, bem como os conteúdos programáticos dentro da carga horária prevista de 75 horas/aula. Dessa forma, por meio da TLD, foram lidos e discutidos os seguintes textos completos ou fragmentos dos textos literários:

Quadro 2 - Obras literárias

\begin{tabular}{|l|l|}
\hline \multicolumn{1}{|c|}{ Número da Roda de leitura } & Nome da obra \\
\hline Roda de leitura I & Civilización y barbárie de Domingo Faustino Sarmiento \\
\hline Roda de leitura II & El matadero de Esteban Echeverría \\
\hline
\end{tabular}

${ }^{7}$ Semestre em que estava o estudante quando cursou a disciplina de Literatura Hispano-Americana II. 
REVISTA X, Curitiba, volume 14, n.3, 158-173, 2019.

\begin{tabular}{|l|l|}
\hline Roda de leitura III & Martín Fierro de José Hernández \\
\hline Roda de leitura IV & Poetisas americanas \\
\hline Roda de leitura V & Amalia de José Mármol \\
\hline Roda de leitura VI & Aves sin nido de Clorinda Matto de Turner \\
\hline Roda de leitura VII & Santa de Federico Gamboa \\
\hline Roda de leitura VIII & Contos de Ricardo Palma e Fray Mocho \\
\hline Roda de leitura IX & Barranca abajo de Florencio Sánchez \\
\hline & Fonte: Elaborado pelos autores. \\
\hline
\end{tabular}

As rodas de TLD eram antecedidas em algumas aulas pela leitura e discussão de textos teóricos que tinham como objetivo contribuir para a apropriação de características relevantes sobre os movimentos literários e obras estudadas. Apesar disso, o foco da tertúlia residia no processo de apreensão de sentidos individuais e coletivos, bem como associação intertextual feitas pelos próprios estudantes.

As aulas dirigidas às rodas de leitura eram iniciadas com meditação laica (RATO, 2011), seguidas pela interpretação coletiva dos textos mediados pelos princípios da TLD. Todas as falas socializadas eram registradas em um livro de memórias da turma, lido ao final de cada roda. Na sequência, eram desenvolvidos textos poéticos em língua espanhola que tinham como objetivo organizar o conteúdo interno de cada estudante por meio do trabalho estético da palavra. Tais textos eram recitados juntamente com expressão corporal para o exercício de diferentes posturas e entonações de voz exigidas no trabalho docente. Ao final da disciplina, foram confeccionados livros autorais e artesanais a partir dos textos elaborados pelos momentos de escrita criativa.

\section{RESULTADOS E DISCUSSÃO}

Como forma de preservação da identidade dos participantes, cada um recebeu o nome de algum tipo de flor em língua espanhola, a saber: Dalia, Margarita, Nardo e Rosa.

As informações sobre os colaboradores descritas na seção metodológica, apresentada anteriormente, auxiliaram na compreensão de fatos relatados pelos participantes, bem como contribuíram para a análise das experiências sociointeracionais de um modo geral.

\section{Relatos sobre as experiências sociointeracionais na turma antes da TLD}

O aporte teórico deste estudo serviu como base para as análises das respostas 
obtidas por meio das entrevistas. Nelas, percebeu-se menções a questões de disputas de poder e processos de silenciamento das falas dos participantes durante interações em sala, principalmente em momentos de debate. Os trechos seguintes apresentam fragmentos das falas dos participantes sobre situações anteriores à utilização da TLD na disciplina de literatura. O primeiro fragmento é extraído da fala da participante Dalia, que revelou o espanto de uma professora ao notar a hostilidade diante do antagonismo no campo das ideias entre a turma durante um debate. Quando perguntada sobre algum fato ou situação que a havia marcado ao longo do curso, Dalia responde:

Já assustamos a professora com debates na aula de tópicos especiais. Ela gostava muito de dividir a turma em dois grupos e a gente tinha que fazer um debate. Um grupo defendendo um tema e o outro criticando aquele tema. Ela não tava acostumada com a nossa dinâmica de sala. Ela assustou porque parecia que a gente ia bater um no outro. (Dalia).

Apesar de reconhecer a reação da professora e de perceber que era proveniente da forma como a turma se relacionava em determinados momentos, Dalia parece não estranhar a reação causada, o que pode sugerir estar acostumada aos momentos de embate gerados por uma visão que se diferenciasse das demais, sendo entendidas apenas como vozes de dissenso (SODRÉ, 2005) naquele espaço. A disputa por poder falar predomina em momentos como o debate e nesse tipo de situação tornam-se evidentes as orientações hierarquizantes daquele grupo, pois, apesar de serem inconscientes, segundo Charaudeau (2001), num debate é possível perceber formas de opressão e de silenciamento. Rosa, por exemplo, observa que nesses momentos havia reduzido acolhimento de opiniões que se estabeleciam como contrárias, como pode ser conferido no excerto de sua entrevista:

\footnotetext{
[...] porque debates viravam briga, né. Então, assim, eu posso, você pode ter uma opinião, eu tenho a minha. Eu discordo de você, mas isso não quer dizer que eu tenho que te desrespeitar, você me desrespeitar. Você tem a sua opinião, eu tenho a minha. Eu acredito que faltou isso, principalmente quando se tinha debates, porque quando você não era $100 \%$, quando $90 \%$ tinha uma opinião e você tinha uma opinião contrária, você praticamente era massacrada. Então eu acho que isso aí foi um algo muito negativo. (Rosa).
}

A percepção de Rosa nos momentos de conflito indicia o comportamento homogeneizante que a escola pode assumir ao não perceber possíveis violências para com as opiniões que se distinguem da maioria, demonstrando o quanto sofria, pois chega a utilizar o termo "massacre" para referir-se à forma como uma opinião diferente das demais pôde ser motivo de repreensão. O sentimento de Rosa pode ainda estar 
REVISTA X, Curitiba, volume 14, n.3, 158-173, 2019.

associado ao preconceito percebido desde seu início no curso, descrito abaixo, quando perguntada sobre um fato ou situação que a havia marcado:

[...] no início me marcou de forma negativa, né, por causa do preconceito, assim... as pessoas viam, via ser uma pessoa, assim, de uma certa idade, né. E até de professores, mesmo, assim, é, achando que essa pessoa não vai passar do primeiro semestre, né, então, assim, e isso me motivou, assim, no início foi triste, mas, que depois disso foi positivo, me motivou, né, a mostrar que não, que eu era capaz e que eu ia seguir em frente e eu ia tá lá no final e foi o que aconteceu. (Rosa).

Rosa supõe que o motivo do preconceito sofrido por ela se relaciona ao fato de ser mais velha do que os demais colegas, porém, havia outros participantes mais velhos na turma e o que os diferenciava era o gênero e a cor. Assim, numa abordagem interseccional, percebe-se que o lugar de fala de Rosa é uma convergência (BIROLI; MIGUEL, 2015) entre ser mulher, ser mais velha e não ser aparentemente branca, embora se defina como tal. O lugar assumido por ela é de alguém que tem consciência e luta contra a hegemonia.

Já para Nardo, um momento de violência relatado deveu-se à sua situação socioeconômica que afetava o acesso à internet. Segundo ele, tudo se deu por um ruído na comunicação durante um trabalho em grupo, no primeiro semestre (antes da TLD), o qual se desdobrou em comentários no grupo de sua turma no WhatsApp:

\begin{abstract}
Só tenho internet na faculdade. Então, eu tinha essa barreira e a questão do trabalho. Que eu tava trabalhando, cuidando da família, tudo.[...] E um dia eu cheguei, teve um trabalho que nós fizemos em grupo. [...] Aí, depois, na época assim, eu tinha ganhado um celular, né, que minha professora tinha me dado um celular que pegava WhatsApp lá na faculdade. Aí, depois, veio uma colega aí, mandou mensagem desagradável e eu vi lá no whatsApp, que eu vi lá, que eu tava vendo lá, vendo sobre mim, falando sobre mim. Eu simplesmente, eu não respondi, não falei nada, mas eu fiquei, assim, muito constrangido, né, porque, assim, devido a esse fato [...]. A pessoa ficou lá falando essas coisas aí, passando essas coisas lá e eu fiquei constrangido. (Nardo).
\end{abstract}

No caso de Nardo, a exclusão passa a ser atribuída à falta de acesso à internet. $\mathrm{O}$ que chama atenção é que, apesar de não se sentir excluído pelos demais, ele passa por uma autoexclusão que "não é parte do sujeito; é induzida pela sociedade. O que o sistema normalmente faz, para amenizar o impacto da exclusão, é dar ao sujeito a ilusão de que sua opção para não pertencer a uma determinada comunidade partiu de sua própria vontade" (LEFFA, 2007, p. 5), pois ele afirma ter escolhido não participar do grupo da turma por opção e silencia (ou é silenciado) ao ler sobre os comentários a ele endereçados naquela rede social. 
REVISTA X, Curitiba, volume 14, n.3, 158-173, 2019.

Após observar que tanto Rosa, quanto Nardo possuíam idade avançada, mas apenas Rosa percebeu-se numa situação de preconceito referente à idade, é possível inferir que o fator idade se acumula sobre outros processos de marginalização como gênero e raça, indicando um ponto de convergência entre possíveis eixos de exclusão naquele espaço e confirmando a necessidade de uma abordagem interseccional para analisar esse tipo de situação (BIROLI; MIGUEL, 2015).

\section{Relatos sobre as experiências sociointeracionais a partir da prática da TLD}

Sobre o uso da TLD na disciplina que eles haviam cursado, observou-se que os momentos de partilha impactaram as relações na turma, na percepção dos participantes, como pode ser conferido nos excertos:

Então, assim é algo que me fazia tanto aprender mais sobre literatura quanto aprender mais sobre o ser humano. (Dalia).

Ó, eu achei que a tertúlia ela mexe muito também com os sentimentos né das pessoas porque aí você, vamo supor, a gente lê uma poesia, mas você pode, dentro daquela poesia, você pode viajar, né, você viaja e você viaja para dentro de si mesmo, né?. (Rosa).

Para Dalia e Rosa, a TLD propiciou uma experienciação com a literatura de forma humanizadora, em momentos em que estavam receptivas à obra literária, resultante do contato com as socializações dos demais participantes que oferecem insumos a partir de suas experiências de vida, e outras possibilidades de encarar uma mesma situação, como é entendido pelo princípio da inteligência cultural (ANDRADE; PEREIRA, 2014).

[...] é, foi claro que facilitou pra mim, porque eu aprendi novas palavras, eu aprendi a comunicar melhor, eu aprendi a falar melhor. Eu sinto, né, que eu aprendi. Eu fiquei mais por dentro da classe. Não é que eu tinha vergonha, assim, da classe, eu não tinha vergonha de falar, mas eu acho, assim, que a gente não tinha a oportunidade de falar pela questão do conteúdo [...], mas era uma coisa que eu estava usando ali na prática, ali na hora, que era uma coisa que eu sabia que eu queria fazer, então, isso daí me ajudou como formação até de um professor, d'eu me preparar pra eu futuramente ser um professor. (Nardo).

Nardo considera que a TLD influiu em seu desenvolvimento em língua espanhola, afirmando que conseguiu "comunicar-se melhor", um possível exemplo do princípio de dimensão instrumental sugerido pela tertúlia, ou ainda, a impressão que teve por saber que uma das condições para a realização dessa metodologia é, sobretudo, acolher a fala da outra pessoa, criando novos espaços de diálogo e podendo falar sobre 
REVISTA X, Curitiba, volume 14, n.3, 158-173, 2019.

qualquer tema, em vez de ser objetificado ou ter sua fala restrita a temas prédeterminados (hooks, 2013). Nardo assume um lugar de alguém que pode falar e participar, nesse caso, o que pode ser atribuído a um ambiente propício gerado pela TLD. Com a prática da metodologia, nota-se também as impressões de superação de processos de silenciamentos, de autoexclusão, bem como de construção identitária e intersubjetiva de si pela linguagem (hooks, 2013).

\begin{abstract}
Vários deles eu não conhecia tão bem. Vários deles eu fui entender nuances nas TLDs e, alguns que eu conhecia, que eu tinha amizade e que por $n$ motivos eu me afastei, eu acabava me tornando um pouco mais humana e conseguia não ter tanto rancor ou tantos motivos para continuar afastada." (Dalia).
\end{abstract}

[...] a gente tinha rixas particulares extremamente estabelecidas, mas que já estão estabelecidas há anos, então a pessoa: 'Ah, fulano é assim porque Deus quis, tá?'. Não é porque ela teve uma questão de vida, porque ela teve um passado, porque ela tem pais não sei o quê. Não, porque Deus quis. E na TLD não, você via que ela era assim, que ela tinha esse pensamento por tudo aquilo que ela que fez parte dela até aquele momento. (Margarita).

\begin{abstract}
Eu acho que sim porque naquele momento ali da TLD, as pessoas ficam mais sensíveis, né, mas não digo mais vulneráveis, mas, assim, mais abertos, né, pra quando tem, assim, aquela memória, né, tem aquele registro, né, da sua vida e você partilha com outro, né. Eu acho que é válida. E eu acho, assim, que faz a gente conhecer o outro de uma outra maneira do que a gente tá acostumado porque a gente, né, que o ser humano, assim, a gente vê e logo faz um pré-julgamento, né, e ali não. Ali a pessoa tá aberta a falar um pouquinho da sua vida, né. Eu achei interessante. (Rosa).
\end{abstract}

Nesses excertos, os participantes sustentam a ideia de que a TLD proporcionou momentos de escuta sensível (CANCHERINI et al., 2011), caracterizada pela empatia na ação de ouvir o que o outro tem a dizer. Isso é característico de um ambiente centrado no diálogo igualitário e na igualdade de diferenças, o que tende a reduzir concepções prévias sobre os colegas e a ressignificar as relações na turma. Além disso, afirma que se abriu espaço para que todos tivessem seu lugar de fala respeitado, reestabelecendo processos humanizadores por meio da escuta sensível e da valorização da diversidade, contribuindo para a formação docente de modo integral, pois entrelaça os conhecimentos técnicos às demais inteligências.

É importante ressaltar que os textos teóricos utilizados no âmbito desse estudo sobre TLD apontam que seus efeitos se dão pela continuidade, pela promoção constante de momentos em que os oito princípios da metodologia serão desenvolvidos no grupo e que a utilização da tertúlia tende não só a diminuir os conflitos como também a aumentar o respeito às opiniões divergentes promovendo espaços mais seguros para a 
construção do diálogo, o que vai ao encontro das observações feitas pelos pesquisadores e do que é dito nos excertos abaixo:

“[...] eu queria, eu senti que chegou o meu momento. Que eu tinha dificuldade na gramática, mas, mesmo assim, eu falava. Porque eu gosto de falar. Eu gosto de falar porque eu gosto de aprender. Então, quando chegou naquela hora, não eu não me senti desafiado, eu senti que foi o meu momento que chegou, aquela hora." (Nardo).

"E, na TLD, a gente teve mais, pelo menos nessa turma em específico, essa questão do respeito. Você tá respeitando o outro como ser e respeitando a história de vida dele. Ele é porque ele é, por tudo que ele viveu até ali. Então eu acho que a tertúlia veio, pelo menos, pra fechar aquele grupo específico em alto. Porque aí sim, a gente começou a se respeitar como indivíduo. A gente também depois se falou, se brigou. Mas, respeitando o outro. É diferente." (Margarita).

O escopo deste estudo buscou analisar as experiências sociointeracionais mediadas pela TLD, portanto, o melhor desempenho dos participantes em relação à gramática não pode ser aferido, porém, os cabe o registro de uso da língua durante todos os encontros de TLD, desde as meditações guiadas até a expressão oral dos poemas produzidos pelos participantes, configurando-se como uma série de interações pela linguagem $(\mathrm{KOCH}, 2005)$. Essas falas também ratificam resultados de pesquisas anteriores sobre a referida metodologia, ainda que em diferentes contextos, estabelecendo diálogo com Flecha (1997) quando afirma que a leitura das experiências socializadas por ele, possuíam elementos de reflexão que poderiam levar à recriação das orientações ali presentes.

\section{CONSIDERAÇÕES FINAIS}

A partir da análise das narrativas dos estudantes e das observações realizadas pelos autores deste estudo, pode-se perceber que a TLD contribui para a promoção do respeito, bem como para a edificação de um espaço acolhedor onde pessoas se sentissem seguras para manifestar ideias divergentes, construídas a partir de seu lugar de existência no mundo.

Por meio dos oito princípios da TLD, percorreu-se um caminho que levou os atores à ressignificação dos espaços de disputa imposta por meio da linguagem, bem como à transformação de relações interpessoais naquela turma. O diálogo igualitário possibilitou que a fala de cada um fosse respeitada desde o início das socializações, as quais levaram em consideração os saberes de experiências prévias por meio da inteligência cultural. 
REVISTA X, Curitiba, volume 14, n.3, 158-173, 2019.

Os resultados aqui descritos levaram em consideração a subjetividade do ser humano, as relações sociais ali estabelecidas e as visões de mundo de cada participante, sendo entendidas como parte de um processo de construção de conhecimento situado e, sobretudo, aberto à discussão. Desse modo, este estudo não deve ser visto como um produto final e sim como um ponto de partida para pesquisas futuras que busquem investigar outras implicações no âmbito das ciências humanas, principalmente no que tange a práticas e ações promotoras de uma educação integral.

\section{REFERÊNCIAS}

ALBUQUERQUE, G. C. S. Utilização da Tertúlia Literária Dialógica na disciplina de literatura hispanoamericana ii do curso de letras/espanhol do IFB - Campus Taguatinga Centro. Anais eletrônicos... Santa Maria: UFSM, GEPEIS, 2016. Disponível em: $<$ http://coral.ufsm.br/gepeis/images/OuvindoCoisas/5OuvindoCoisas/ANAIS\%205\%20OUVIN DO\%20COISAS_2016.pdf $>$. Acesso em: 20 ago. 2018.

AMARAL, M. F. Lugares de fala: um conceito para abordar o segmento popular da grande imprensa. Contracampo, n. 12, p. 103-114, jan./jul., 2005. Disponível em: < http://periodicos.uff.br/contracampo/article/view/17388 >. Acesso em: 18 nov. 2018.

ANDRADE, A. P. S. S.; PEREIRA, J. C. Tertúlia literária dialógica: teoria e prática. Guia didático a partir de uma experiência de extensão no Programa Nacional Mulheres Mil. Brasília: Editora IFB, 2014.

BARDIN, L. Análise de Conteúdo. Lisboa: Edições 70, LDA, 2016.

BIROLI, F; MIGUEL, L. F. Gênero, raça, classe: opressões cruzadas e convergências na reprodução das desigualdades. MEDIAÇÕES, Londrina, v. 20, n. 2, p. 27/55, jul./dez. 2015.

Disponível

em: $<$ http://www.uel.br/revistas/uel/index.php/mediacoes/article/view/24124/G\%C3\%AAnero\%2C \%20ra\%C3\%A7a\%2C\%20classe\%3A\%20opress\%C3\%B5es\%20cruzadas\%20e\%20cconverg\% C3\%AAncias\%20na\%20reprodu\%C3\%A7\%C3\%A3o\%20das\%20desigualdades $>$. Acesso em 15 ago. 2018.

CANCHERINI, Â. et al. A escuta sensível como possibilidade metodológica. Revista Pesquisa Qualitativa, Franca, v. 4, 2011. Disponível em: $<$ https://ojs.franca.unesp.br/index.php/caminhos/article/view/619/0 > . Acesso em: $10 \mathrm{fev}$. 2018.

CHARAUDEAU, P. Uma Teoria dos Sujeitos da Linguagem. In: MARI, H. et al. Análise do Discurso: fundamentos e práticas. Belo Horizonte: Núcleo de Análise do Discurso - FALE/UFMG, 2001, p. 23-37. Disponível em: $<$ http://www.letras.ufmg.br/padrao_cms/documentos/nucleos/nad/CHARAUDEAU\%20$\% 20$ Uma\%20Teoria\%20dos\%20sujeitos\%20da\%20Linguagem.pdf $>$. Acesso em 7 out. 2018.

FLECHA, R. Compartiendopalabras - El aprendizaje de las personas adultas a través del diálogo. Barcelona: Paidós, 1997. 
REVISTA X, Curitiba, volume 14, n.3, 158-173, 2019.

FRANÇA, V. R. V. Convivência urbana, lugar de fala e construção do sujeito. Revista Intertexto, Porto Alegre, UFRGS, v.2, n. 7, p.1-10, 2001. Disponível em: <https://seer.ufrgs.br/intexto/article/view/3392>. Acesso em: 12 ago. 2018.

GAVIOLI, A. V.; MELLO, R. R. Contribuições da tertúlia literária dialógica para a superação de concepções edistas e construção de uma nova educação de jovens e adultos. Cadernos da pedagogia. UFSCar. Online, v. 4, n. 7, p. 37-55, 2010. Disponível em: $\quad<$ http://www.cadernosdapedagogia.ufscar.br/index.php/cp/article/viewFile/176/102>. Acesso em: 20 out. 2018.

GIROTTO, V. C.; MELLO, R. R. O ensino da leitura em sala de aula com crianças: a tertúlia literária dialógica.Inter-ação. UFG: Online, v. 37, p. 67-84, 2012. Disponível em: <https://www.revistas.ufg.br/interacao/article/view/18869>. Acesso em: 16 dez. 2018.

GONTIJO, S. B. F. et al. Inovações na organização do trabalho pedagógico da educação superior: a experiência com a tertúlia literária dialógica no estágio supervisionado no curso de Pedagogia. In: $\sigma^{a}$ CONFERENNCIA FORGES. Campinas: FORGES, 2016. Disponível em: < http://www.aforges.org/wp-content/uploads/2016/11/27-Simone-Gontijo-et-al_Inovacoes-naorganizacao-do-trabalho.pdf $>$. Acesso em: 11 set. 2018.

hooks, bell. Ensinando a transgredir: a educação como prática da liberdade. Marcelo Brandão Cipolla. São Paulo: Editora WMF Martins Fontes, 2013.

KOCH, I. G. V. A inter-ação pela linguagem. São Paulo: Contexto. 5. ed., 2000.

LEFFA, V. J. Pra que estudar inglês, profe?:Auto-exclusão em língua-estrangeira. Claritas, São Paulo, v. 13, n. 1, p. 47-65, maio 2007. Disponível em: $<$ http://www.leffa.pro.br/textos/trabalhos/auto_exclusao_le.pdf $>$. Acesso em: 12 out. 2018.

MAGALHÃES, S. M. A Tertúlia Literária Dialógica no ensino de espanhol: reflexões sobre identidade e letramento. 2017. 130 f. Dissertação (Mestrado em Linguística Aplicada) - Universidade de Brasília, Brasília, 2017.

MOUGEOLLE, L. O conceito de “interseccionalidade".In: Portal de Sociologia. Disponível em: <http://www.sociologia.com.br/o-conceito-de-interseccionalidade/>. Acesso em: 30 set. 2018.

PINTO, J. P. Da Língua-Objeto à Práxis Linguística: desarticulações e rearticulações contra hegemônicas. Linguagem em Foco, Fortaleza, v. 2, p. 69-83, 2011. Disponível em:

$<$ https://perspectivas.letras.ufg.br/up/298/o/Artigo\%20Joana\%20Linguagem \%20em\%20Foco\% 20-\%20versao\%20final.pdf $>$. Acesso em: 12 out. 2018.

RIBEIRO, D. O que é lugar de fala?Belo Horizonte: Letramento, 2017.

SODRÉ, M. Por um conceito de minoria. In: PAIVA, R.; BARBALHO, A. (Orgs.) Comunicação e cultura das minorias. São Paulo: Paulus, 2005. Disponível em: $<$ https://www.ceap.br/material/MAT16042010145008.pdf>. Acesso em: 15 set. 2018. 